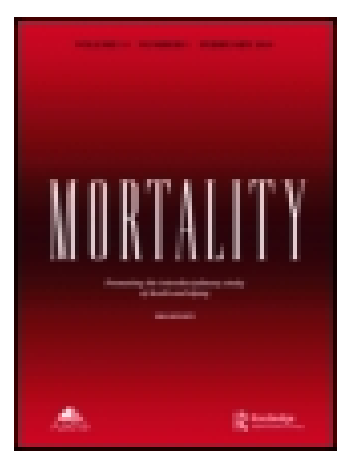

Mortality

Promoting the interdisciplinary study of death and dying

ISSN: (Print) (Online) Journal homepage: https://www.tandfonline.com/loi/cmrt20

\title{
Intimate relationships and Suicidal Behaviour of Men in Bangladesh
}

\section{Anisur Rahman Khan, Najuwa Arendse \& Kopano Ratele}

To cite this article: Anisur Rahman Khan, Najuwa Arendse \& Kopano Ratele (2021): Intimate relationships and Suicidal Behaviour of Men in Bangladesh, Mortality, DOI: 10.1080/13576275.2021.1879755

To link to this article: https://doi.org/10.1080/13576275.2021.1879755

曲 Published online: 03 Mar 2021.

Submit your article to this journal $\pi$

Q View related articles $\longleftarrow$

View Crossmark data $[\pi$ 


\title{
Intimate relationships and Suicidal Behaviour of Men in Bangladesh
}

\author{
Anisur Rahman Khan ${ }^{a}$, Najuwa Arendse ${ }^{b}$ and Kopano Ratele ${ }^{b}$ \\ ${ }^{a}$ Department of Sociology, East West University, Dhaka, Bangladesh; 'Institute for Social and Health \\ Sciences, University of South Africa \& South African Medical Research Council-University of South Africa \\ Masculinity and Health Research Unit, Cape Town, South Africa
}

\begin{abstract}
Suicidal behaviour (e.g., suicide and suicide attempt) is a multifaceted phenomenon which often draws on several social and psychological contexts. This research examines how men's suicides and attempted suicides are embedded in the contextual praxis of intimate relationships in Bangladesh. Qualitative semi-structured interviews were undertaken with family members, close relatives, and friends of 37 men who died by suicide or attempted suicide. This research's findings identify five key risk factors associated with men's suicide and attempted suicide, namely: troubles over the designated family provider's responsibilities; troubles emanating from second marriage; betrayal of loyalties; complications in non-marital relationships; and feelings of no control over wife. Each theme suggests that men who died by suicide or who attempted suicide found it challenging to balance their culturally expected (hegemonic) masculine image with their intimate relationships. Suicide and attempted suicide surfaced as a consequence of such challenges in their life. Efforts are suggested to lessen the burden on men's masculine expectations and promote an egalitarian social space in order to reduce suicide risk in men.
\end{abstract}

\section{KEYWORDS}

Suicide; suicide attempt; men; hegemonic masculinity; intimate relations; Bangladesh

\section{Introduction}

Suicidal behaviour refers to the inclination to kill oneself (Bantjes \& Kagee, 2013) and includes not only acts of completed suicide, but feelings, ideas, thoughts and attempts of suicide (Schrijvers et al., 2012). Up to 1 million people die by suicide globally every year (World Health Organisation, 2014). For every suicide, approximately 30 more attempts occur (Bachmann, 2018), and at least $40 \%$ of these individuals have a history of taking their own life (Hawton \& van Heeringen, 2009). As a public health issue, the Sustainable Development Goal 3.4.2 targets to reduce suicide by $33 \%$ in 2030 (Pollock et al., 2020). Globally, suicidal behaviour presents a gendered facet where men commit more suicide than women (Curtin et al., 2016) but women make more attempts than men (Schrijvers et al., 2012).

Suicidal behaviour is a multifactorial phenomenon often embedded in a wide range of socio-cultural contexts, perspectives, and life events (Hjelmeland \& Knizek, 2019;

CONTACT Anisur Rahman Khan arkhan@ewubd.edu Department of Sociology, East West University, Dhaka, 
Scourfield \& Evans, 2014). Interpersonal or intimate relationships, generally recognised as a type of personal relationship regarded as 'close' and broadly includes numerous associations between friends, sexual partners, family and kin (Gillies, 2003, Jamieson, 2011), may act as a protective and risk factor to suicide (Delgado, 2012). A healthy intimate relationship is deemed pivotal in people's lives (Roberts \& Robins, 2000), and relationship quality impacts on all facets of intimate interactions (Kazan et al., 2015). In the sociological classic Le Suicide (1897/2005), Durkheim suggested from a Western societal perspective that social ties such as marriage act as a signpost of intimate relationship by protecting individuals from suicide risk through their integration into society and providing them with moral regulation. In contrast, divorced or separated individuals increasingly succumb to suicide risk due to the break in protective bond between individuals (Durkheim, 1897/ 2005; Stack, 1982). Such a Western assumption that marriage protects against suicide may not be representative of Eastern marriages where conflict, stress and tension are known to occur (Mayer, 2012). Generally, South Asian culture views interpersonal disputes, marital conflicts or domestic or intimate partner violence, complicated gender role expectations, and culture of extended family system, amongst other factors, as contributing to suicidal behaviour (Khan, 2002; Khan et al., 2011; Rathod et al., 2015).

Whilst intimate relationships act as an important protective factor and a source of stability and emotional support, the persistent troubles in intimate relationships act as a precipitating factor for suicidal behaviour (Evans et al., 2016; Ide et al., 2010; Kazan et al., 2015; Scourfield \& Evans, 2014). The relationship breakdown or interpersonal conflict leaves men more susceptible to suicidal risks than women (Evans et al., 2016; Scourfield \& Evans, 2014). The risks increase within relationships that undergo continuous turmoil (Wasserman, 2016a). Relationship strains tend to produce different meanings and contexts for men and women (Shiner et al., 2009). In particular, both separated and divorced men are at much higher risk of suicide than women, because men are more dependent on their partners for emotional and social supports (Platt, 2017; Wyder et al., 2009). This risk, however, progressively reduces with age. Women tend to receive more support than men from their wider social networks during relationship trouble that acts as a protective and powerful shield against women's suicidality (Wyder et al., 2009).

This paper is centred in the country of Bangladesh, South Asia. Here, family life plays a central role in people's lives and the formation of intimate relationships or marriages. Although urbanised families are becoming increasingly open to their children's premarital romantic relationships and allowing them to choose a spouse, arranged marriage is the prevailing norm across all classes (Bhandari \& Titzmann, 2017; Yeung et al., 2018).

Families in South Asia are fundamentally extended, patriarchal, patrilocal and intergenerational with few exceptions (Dasgupta, 2015; Yeung et al., 2018). In the case of children forming nuclear households, they maintain a strong sense of commitment to extended family norms, practices and ideologies (Bhandari \& Titzmann, 2017). The authority and responsibilities in an extended family are distributed in terms of age and gender. Usually, the eldest male in the household holds maximum power over other members, and the eldest female holds substantial power over sons and other women (Dasgupta, 2015). Due to the patriarchal nature, South Asian families typically maintain a male-dominated gender hierarchy, awarding women lower status and treatment than their husbands or other male members in family lives (Ahluwalia et al., 2015; Moham, 2020). 
Since the interpersonal or intimate relationships at the micro-level (e.g., family) maintain a linkage with the broader social (gender) structure (Shah, 2016), male-dominance /patriarchy/hegemonic male norm essentially dictate the course of intimate relationship in South Asia, although this does not mean that women are absolutely powerless, rightless, uninfluential or resourceless (Srivastava \& Roy, 2011). Specific to Bangladesh, there is no conclusive understanding about the ideal or hegemonic masculine norm. Leading scholars have identified some ideal versions of hegemonic masculinity, such as breadwinner or primary provider to the family; dominant, powerful and authoritative over family matters and women; physically and sexually competent, protector, defender and impassive; among others (Anwary, 2015; Hasan et al., 2017; Imtiaz, 2013; Khan et al., 2008; Khan \& Townsend, 2014).

This paper considers intimate relationships from the typical gender perspective as a close association between a husband and a wife, and between a male and female who are in a (non-marital) romantic/love relationship. It intends to explore the way complexities and contestations in interpersonal relationships act as an instigating factor for both suicide and suicide attempt of men in Bangladesh.

Although suicide is a serious public health issue in Bangladesh, there is no national surveillance mechanism (Khan, Ratele, Arendse et al., 2020). The dearth of empirical research obstructs a comprehensive and reliable scientific estimation of the prevalence on suicide or suicide attempt (Bagley et al., 2017; Mashreky et al., 2013). Survey estimates indicate that more than 10,000 people die due to suicide every year in Bangladesh and the average rate of suicide lies between 7.3 and 14/100,000 population (Mashreky et al., 2013). Bangladesh is reported to be one of the few countries in the world where women commit more suicide than men (Bagley et al., 2017; Pollock et al., 2020), but the exact gender ratio is yet to be precisely explored for the country (Arafat, 2019). World Health Organisation's (n.d.) recent data on age-standardised suicide rates (per 100,000 population) and the large community-based survey conducted by Khan et al (2020) marks a declining trend of male suicide rates and a sharp decrease of female rates in Bangladesh which marks men as a risky group. Considering the higher rate of male suicide rate globally, the diverse risk factors associated with the male suicidal phenomenon (Coleman et al., 2011) and the increased trend of male suicide in Bangladesh, it is necessary to explore the contextual praxis of suicide and attempted suicide in Bangladesh. From that perspective, we made an attempt to delve into exploring the context of intimate partner relationship in men's suicide and suicide attempts in Bangladesh.

\section{Materials and methods}

\section{Study location}

This paper is a partial reflection of a broader study, titled 'Men's suicidal behaviour and masculinity in Bangladesh', which was conducted in Jhenaidah District, South-West Bangladesh. Among several districts of this region, Jhenaidah is repeatedly mentioned as one of the suicide-prone areas in the country (Khan et al., 2020; Rahman, 1988; Rahim, 2015). Suicide records in other regions are near absent (Jahan, 2019). Nonetheless, it is pertinent to explore why the prevalence of suicide is high in this district. Broader assumptions suggest that the region is not prone to natural calamities or disasters; 
therefore, people demonstrate the least capacity to sustain difficult emotional and hard conditions (Jahan, 2019). Jhenaidah is traditionally an agriculture surplus district where most of the households are involved in farming (Jahan, 2019; Rahman, 1988). The availability and unsafe storage of pesticides in rural areas are also strongly associated with the widespread use of pesticide as a method of suicidal behaviour in the district (Jahan, 2019; Sadek et al., 2019). From 2010 to 2018, 3,152 suicides and 2,2675 attempted suicides were reported and officially recorded in Jhenaidah district. This reporting confirms poisoning through pesticide ingestion as the most widely used method for suicide attempt (91\%) and hanging is the common method of suicide (53\%) (Khan et al., 2020).

We purposefully recruited research participants from several rural areas using the referral from Society for Voluntary Activities (SOVA), a non-government organisation working to reduce suicidal behaviour in this district (Khan et al., 2020). Unlike other areas in Bangladesh, Jhenaidah district administration maintains official records on suicide and suicide attempt as routine, official duty. It is due to SOVA's successful advocacy efforts that concerned government agencies collected and recorded such vital information (Khan et al., 2020).

\section{Participants}

The study comprised 37 participants across two groups: 17 male participants who attempted suicide, and 20 close family members/friends/close relatives of men who died by suicide. Suicide survivors ages ranged from 18 to 55 years $(M=30)$, with 10 participants aged 18-30 years, 6 aged 31-50 years and 1 participant was 55 years old. Sixteen (16) participants attempted suicide once and the other made two attempts. None of them left any suicide notes during their attempts. Methods used in suicide attempts included pesticide ingestion (17) and hanging (1). These attempts were made between 2013 and 2018.

Out of the 20 deceased males; 10 were aged 17-30 years and 10 were between 31 and 55 years $(M=29.7)$. The majority died by hanging (13), followed by poison/insecticide ingestion (6) and jumping from a height (1). One of the deceased persons had a history of suicide attempts. All the incidents of suicide took place between 2014 and 2018. We interviewed one family member, friend, or close relative of each of the deceased men who took their own lives.

\section{Procedure}

The first author, a native of the area/country, plainly explained the purpose of the study to the prospective participants, and invited them to participate in the study at a preferred time and place. Following informed consent, the first author carried out a qualitative semi-structured in-depth interview in order to explore the experiences of the participants. The first author conducted the interviews in the local language, Bangla, and each interview lasted between 35 and 120 minutes. With participants' consent, all interviews were audio recorded. The fieldwork took place between December 2018 and February 2019. We also collected relevant demographic information of the participants. 


\section{Ethics}

Ethical clearance was granted by the University of South Africa (Ethical Clearance Code: Ethical Clearance Code: 2018-CHS-0114). As per ethical guidelines, the first author briefed the participants about the risks of participating in the study, including their rights to refuse to participate and withdraw at any moment. Participants gave their consent to participate in the study. In return, they were assured of confidentiality and anonymity by using pseudonyms throughout the research process. A professional counsellor accompanied the research team during data collection. Further provision was available to transport the participants to a nearby public hospital in the event of an emergency although no one required this service.

\section{Data analysis}

The first author and a research assistant from Bangladesh transcribed the audio recordings verbatim in Bangla. The English translation was done by professional translators. We used Braun and Clarke (2006) thematic analysis framework to analyse the data. All the researchers read the entire translated interview transcripts several times to familiarise themselves with the data. We concentrated slowly and line by line on the transcribed interviews and carefully identified the regular-recurring experiences, perceptions, and feelings of the participants. Using such an inductive process we got a firm grip of the data and identified the common themes. In carrying out thematic analysis, we sought answer to the research question, 'How do the strains generated from intimate relationship link to men's suicide and attempted suicide?'

\section{Findings}

We categorised the complex interplay of intimate relationships and their linkages to men's suicide and suicide attempts under the following five broader themes.

\section{Troubles over provider/breadwinner responsibilities}

In some cases, men were seriously entrapped by their 'provider responsibility/breadwinner role within the household', a uniform social norm associated with ideal and dominant masculine standards (Macia et al., 2011). When the social context forced men to believe that they are not meeting such masculine ideal/hegemonic standards, they might feel a sense of shame and defeat (Platt, 2017). For example, Zohur was brought up in a typical Bangladeshi extended family. Since he lost his parents at a young age, his elder brother and elder sister-in-law raised him providing him the highest level of education despite their poverty. After graduating from university, Zohur worked at a commercial bank. Out of the highest sense of reciprocal familial responsibility, Zohur thought it was his solemn masculine obligation to financially support his niece (daughter of his elder brother). Therefore, Zohur's case was one of expectation of men to contribute to the promotion and management of the family and fulfil household providing roles in an extended family culture in Bangladesh (Karim et al., 2018). Zohur's reciprocal masculine obligation soon turned into 
a serious contention once he got married. After marriage, his wife mentally pressured him not to support his niece. He failed to cope with the ongoing conflict in his marriage which caused him to end his life.

This case resonates with the literature that having a quarrelsome wife is perceived as a sign of failure in manhood (Omololu et al., 2004). The embargo placed on Zohur's masculine responsibility to support his niece is equated with a typical South Asian context which represents a popular discourse, 'women are women's worst enemies' (Gangoli \& Rew, 2011 , p. 423). Women wish to control men's masculine domination in the family, and they get involved in rivalry and competition with other women to sustain their power over men (Mittra \& Kumar, 2004). Zohur's elder sister-in-law (Shufia) recalled:

Zohur kept his niece at his workplace, because his wife could not stand her at all. She didn't even give her food properly. [--] His wife had a government job, she didn't have any shortage; but still, she used to quarrel with Zohur. She used to say that he is taking care of someone else's daughter [--]. Gradually, the problems between them increased. [-] I never thought that an educated woman could fight like that.

(Shufia) further recalled:

His wife thought he was giving all his money to us, but it was not the situation. At some point we said that you do not need to help my daughter. If you are happy then we are happy. But still he loved her. He thought of it as his family responsibility. We wanted to separate him, but he didn't let that happen because this is what he has seen men are doing in the community.

Taher was a capable man to provide for his family. At one stage he had lost much of his physical energy due to severe stomach pain that drastically reduced his ability to earn an income. Poor health or chronic illness of men leads to far-reaching, damaging, demoralising and undignified impacts on hegemonic/ideal assumptions of masculine male roles (Mathewson, 2009). Severe and chronic physical illness serves as a precipitating factor for suicide morbidity (Lönnqvist, 2016). The physical illness of Taher became a constant conflicting issue between him and his wife in their poverty-stricken family. Failure to live up to the expectations of a breadwinner emasculated Taher from his supposedly dominant and powerful position. To suppress pressure from his wife, he sometimes perpetuated violence against her wife that further aggravated their relationships. Violence is often used by men when their masculinity is in trouble (Khan \& Khandaker, 2017). At last, Taher committed suicide to get rid of shame and embezzlement. His wife, Sultana, recalled the context of the suicide of her husband:

When the family is in fragile, no one listens to each other. I would quarrel with him too and used to tell him, he is not a man who can earn a livelihood! He is a man, I am causing him anger, I used to argue with him face to face and then he used to beat me up. [--] I didn't say anything intentionally to hurt him. But yes, I had said a lot of things in anger, maybe I had said that he can't earn, maybe I had said, he is sitting idle at home and can't go out for work. Now I think I shouldn't have said those things. He might have gotten disheartened and committed suicide.

These men encountered serious troubles in their intimate relationship when performing their socially expected, family provider/breadwinner responsibilities which elevated their risk for suicidal behaviour. These cases exemplify an escape from the intolerable view of self and the connected negative effects (Coleman et al., 2011). 


\section{Inviting troubles through polygamous marriage}

Bangladesh is a Muslim majority country where $90 \%$ people follow the Islamic faith (Bangladesh Bureau of Statistics, 2015). Although Bangladeshi law allows polygamy for men under certain conditions, the trend of such marriage is on the decline. It is punishable if procedure, such as consent from the first wife, is not followed (Amin \& Das, 2014). Polygamous marriages, where practised, often invite serious consequences for both men and women in families (Brooks, 2009).

Morshed, a married rural businessman developed an extramarital relationship with a divorced woman whom he later married. Following the incident, his first wife left him. His second wife quickly took control of the family and burdened him with excessive demands for money and materials. In order to meet the demands of his new wife, Morshed accrued huge debts. Meanwhile, his wife also started meeting her ex-husband secretly and maintained an extramarital relationship. She also put pressure on Morshed to divorce her so that she could remarry her ex-husband. Morshed felt overwhelmed with regret for leaving his first wife and ended his life. His elder sister-in-law (Shanti) commented:

He was perplexed. He confessed the mistake he made by leaving his good-natured wife and getting married to a divorced woman. He started recollecting the execration of his former wife who once told him that he would pay for his sins. And, it happened most extremely.

Javed was continuously on bad terms with his wife regarding family matters. At some point, he married again to punish his first wife but, instead, it had an adverse effect on him. Following the incident, his first wife and son forcibly took control of the entire family and put pressure on him to divorce his new wife, and so the second marriage became a source of mental pain. Finally, he turned to suicide to resolve his troubles. His first wife, Dolly, acknowledged her misbehaviour with her husband before the suicide:

Following that incident (second marriage), my son and I got extremely angry with him and took over all familial authority. We stopped him giving money. [-] He lost interest in the family. He used to move to and fro before suicide. We did not pay any respect to him.

Moin also had a very bad term with his wife and married again to take revenge against her. Instead of the second marriage improving the situation it aggravated it. The relationship between the two wives had created havoc in his life. He attempted suicide to rid him of his problem but survived. Moin recollected the impact of his decision:

[-] (second marriage) I do not know whether that was wrong or right. It aggravated the internal environment of the family. It brought over havoc between both my wives. My situation got even worse. [-] At that point in time, I muttered to myself, "Neither am I going to see your face, nor will you mine!"

Men in the study who married second time invited multifarious troubles in their family life which they only negotiated with an extreme lifetime price. The decision for a second marriage (polygamous) had a devastating impact on men and it could not improve or fix the existing intimate relationship. It rather invited a lot of troubles to the family. 


\section{Betrayal of loyalties}

Some relationships grew more problematic due to the betrayal of loyalties. The betrayed spouses suffered from loss of meaningfulness in life, and their helplessness may erode the will to live by invoking suicidal behaviour (Spring \& Spring, 1997). Distrust or betrayal affects marriage in varied ways as the stability of marriage depends on the fulfilments of expectations and loyalties between the partners (Bhuiya et al., 2005).

Naqib married his girlfriend who belongs to another religion. This marriage was not accepted by his family and they had to live in a neolocal setting away from his village. After a few months, Naqib noticed that his wife became involved in another relationship. He tried to free his wife from this relationship but failed. He expressed his frustration in the following manner:

I found that she had no time for me. [-] Because I loved her. I expected her to be changed. At one stage, I found she does not want to change. I realised that she had no respect for her husband. [-] There has been an epidemic of extramarital love in our society. A woman can destroy a man, and a woman can uplift a man as well. Suicide among men will increase if women misuse men's trust and true love.

Naqib thought that if he left his wife and returned to his village that he might feel some relief. Unfortunately, his village was unwelcoming and imposed more pressure for him to leave. Eventually, failing to cope with entrapment created from both the sides (wife and family members), he attempted suicide. Naqib informed:

I left her and came back to my village home. Nobody welcomed me. They were very harsh with me as I married someone (different) Hindu religion. Moreover, my present relationship with my wife was not unknown to them. Everybody here was very ill-behaved with me and blamed me for my own mistakes. I felt so bad. I saw no hope anywhere. I lost all hope and decided to leave the world.

Chitra confessed to her husband the she had extramarital relations with another man when the sexual problems with her husband grew worse. Chitra's husband tried to convince her to leave the relationship, but she did not. As a result, out of a deep sense of shame and frustration, her husband committed suicide. Chitra said:

I got deeply involved in affairs. It was not possible to come back. Finally, he started threatening me by saying if I continue that relationship, he would commit suicide. I thought this is not unusual to his character. Earlier he did so several times. But this time he did so. [-] I think I was not well behaved with him. I regret my deeds.

Chitra mentioned that reactions of family members and community people about this issue also made her husband feel shame and disgust. Family members, particularly his elder-sister-in-law, intervened the matter several times and suggested to normalise the matter. Chitra informed:

His elder-sister-law advised him several times to go to the doctor for treatments. He never liked it. I understand it used to hurt his masculinity. [-] Moreover, our relationship strain was not unknown to our knit community. People used to pass bad comments at him. It also hurt him. [-] My husband is no more. I now realise the need of my husband. It is painful not having husband. 
The involvement of the wife in an extramarital relationship indicates a weakness in the masculine image and a clear reflection of absence of trust and commitment in relationships. It is a deep sense of pain and dejection for men, an appropriate context for suicidal decisions.

\section{Complications in non-marital romantic relationships}

Marriage is considered more of an obligation than an individual's personal decision in Bangladesh (Sultana \& Karim, 2013). The acceptance of premarital romantic relationships in Bangladesh are more common in the cities and educated classes, and rare in rural areas (White, 2017). Few men in the study who were involved in premarital romantic relationships encountered serious repressions from their family members due to overriding traditional Bangladeshi ideology against love marriage.

Masud was in a relationship with a girl for long time. Both of them decided to marry and expressed their desire to their families. Masud's family did not agreed to the proposal and his father physically punished him for proposing it. At one stage, they ran away from home and took shelter in a relative's house. His father fetched him and forcefully married him to another girl. Knowing that, Masud's girlfriend attempted suicide but survived. When Masud came to know about the suicide attempt of his girlfriend, he also made an attempt but survived. In all respects, this relationship ended in failure. Masud recollected the episode before his attempt:

I got to hear that my lover had tried to slit her wrist and feet with a razor blade. She also tried to hang herself to death. It felt to me like she was trying to end her life for me. So, what would I do with my life, staying alive? [-] Then I drank the whole bottle of poison under my possession.

Karim was in a romantic relationship with his aunt's daughter. Consanguineous marriages (close kin marriage) is common in Bangladesh, though not encouraged (Shenk et al., 2016). Karim encountered obstructions by his family members about his relationship. One day, he challenged his father and expressed his determination to marry her upon which his father tortured him mercilessly. After the incident, he attempted suicide out of hopelessness and dejection. Scholars noted that traumatic events such as physical and mental abuse are strongly connected with suicide (Wasserman, 2016b). Karim said:

It was so humiliating. I decided to commit suicide. I found that as a man I have no space in my world. I found pesticide at hand and swallowed a bottle of it. I started screaming and everyone at home came to know that. Immediately, they took me to the hospital. It took around a month to completely recover.

Men's (non-marital) romantic relationships get succumbed to failure when cultural expectations receive more priority than personal desires and aspirations. It is always difficult to go against the decision of the existing head of the family (e.g., father) as he holds strong masculine hegemony over other members of the family. Men who demonstrated suicidal behaviour were often overrun by a superior hegemony in family settings.

\section{No control over wife}

Men's socially distinguished honour, reputation, agency and masculine ideals are severely tarnished when they fail to control their spouses (Silberschmidt, 2001). Failing to control 
their spouses is a subversive indicator that equates with the feeling of less of a man (Canham, 2009). Few men had lost control over their wives. In some cases, they were even controlled by their wife which created strain and subsequently it led to suicidal behaviours.

Arun always had an adjustment problem in his 10-year marital life. He was unable to meet his wife's demands with his small income. His wife was always very rude to him concerning all matters. Due to Arun's affectionate nature towards his wife, he could not control her. Eventually, having encountered several unwanted pressures from his wife, he decided to end his life. His mother, Sandha informed;

Although it was very difficult for my son (Arun) to meet her demands with the income from his small business, he continuously tried to fulfil her demands. However, her demands were constantly increasing. [-] Maybe he was destined to die this way. A woman has to count many things. My daughter in law did not do that. She did not even have any sorrow feeling. My son tried his best to defend his family and failed. He sacrificed his life for his love.

Sharif was also very enamoured by his wife. He used to spend a major portion of his income to meet his wife's demands. Sharif did not have any control over her, rather she humiliated him on several occasions. Moreover, she often travelled her natal home and expressed no interest to return. The day before he carried out suicide, Sharif attempted to fetch his wife from her natal home. Sharif's father said:

He (Sharif) was like a henpeck. You do not find any problem unless your wife equally understands the value of love from her husband. That was the problem in my son's case, which eventually pushed him to death.

Biplob could never get on good terms with his wife. From the beginning of his marriage, his wife was antipathetic to maintaining physical relations with him. His wife was also on bad terms with her mother-in-law and never cared for the family. Moreover, she frequently visited her natal home with no interest in returning to her marital home. In turn, Biplob became violent with his wife. At one point, his wife with the help of her family members lodged a domestic violence case against Biplob which they proposed to withdraw should Biplob agree to become a househusband. As a man, Biplob found the proposition disgraceful, a breach of the masculine norm. Instead, he spent a lot of money and divorced his wife. All these troubles took place in quick succession. Due to his failure to control his wife, he attempted suicide. Biplob recollected some of his griefs in the following manner:

I thought I would have a good wife, a happy family. But everything was the other way around. [-] It felt really bad thinking about what was happening. I married by my choice, carefully. Thought that she would look after everything. But what is happening? [-] Taking all these into account, I admitted defeat, [-] decided that I won't keep this life anymore.

Due to the patriarchal nature of Bangladesh society, men tend to maintain and control the power and resources within the families (Chowdhury, 2009), but this was not the case for some men as they could not manoeuvre their masculine or patriarchal ability to exercise authority and control and finally accepted extreme defeat in life. 


\section{Discussion}

Within the broader gender framework of interpersonal relationship, five thematic factors appear to have been critical contributors to suicide and suicide attempt of men in this study.

The first theme of study troubles over provider/breadwinner responsibilities provides evidence that men experience difficulties when they fail to deliver on socially expected masculine norms. These masculine norms entail a combination of various roles and expected behaviours associated with manhood in a particular culture (Ragonese et al., 2019), and one of the ideal/hegemonic norms requires men to be the primary financial providers of their families (Ragonese et al., 2019). Men adhering to hegemonic/ideal masculinity often fail to cope with loss, disgust and shame. Here suicide is generally their last response such to distress (Möller-Leimkühler, 2003). Tensions in men's traditional masculine role as provider are often associated with suicidal behaviour (Adinkrah, 2012; Andoh-Arthur et al., 2018; Rivers, 2014). Two specific cases, namely Zohur and Taher, mentioned in this paper indicate that men were in no way encouraged by their spouse to financially support their extended family life. Spouses who are not supportive often elevate a risk for the suicidal persons who hanker after love, affection and consolation (Wasserman, 2016a). In the case of Zohur we noticed that the spouse created an embargo on her husband not to render financial support to his extended family member. This is an example of common domestic strife and conflict generated by women from different generations living in the extended Bengali family (Donner, 2014). Often intra-gender, inter-generational family and household relationships are complicated and detrimental to individuals and families (Vera-Sanso, 1999). Overall, both the cases (e.g., Zohur and Taher) highlight that men failed to perform socially expected masculine provider/protector/ defender role, a raison d'être in an extended family which stood as a cause for their suicidal behaviour.

The theme troubles invited by second (polygamous) marriage attests polygamous marriages were unwelcome by the men's family, resulting in complicated consequences. Beginning from Emilie Durkheim's proposition embedded in Le Suicide (1897/2005), subsequent studies have echoed that marriage acts as a protective factor against suicide for its stabilising or supporting role within the context of social/intimate relations (Griffiths et al., 2008; Wyder et al., 2009). The specific findings under this theme inversely confirms the protective power of marriage as it stands against the conventional sociological law postulated by Emilie Durkheim. Past research indicate the negative effects of polygamy on men, entailing the fact that marriage does not provide immunity to men. A Nigerian study confirms that family disruptions occurs due to polygamous marriage and it places the men under psychological distress (Olley, 2004). A study on Arab Bedouin polygamous men confirm that such men suffer from higher-level mental health problems such as somatisation, obsession-compulsion, depression, anxiety, paranoid ideation, psychoticism and interpersonal sensitivity, among others. All of these factors are strongly attributed to suicidality. This study further confirms that family functioning is disrupted and marital satisfaction weakens due to men's polygamous practices (Al-Krenawi et al., 2006). Our conviction is that if a relationship within the marital framework no longer provides what it requires, it could lead to dissolution or formation of a more fruitful partnership (White, 2017). Several men in this study wanted to form new relationships because the existing 
relationship could not meet their demands and aspirations. In Bangladesh, marriage is thought as an important source of aspiration and hope, but it often raises varied and clashing situations on both partners if it fails to meet the expected aspirations and hope (Rao, 2012). Cases of Morshed, Javed and Moin, cited under this theme, are seen to succumb to conflict and eventually suicidal behaviour in disruptive ways. The decision of the second marriage of men brought turbulence to family functioning and dissatisfaction between the partners.

The theme betrayal of loyalties reasons the manner in which men encountered shame concerning the engagement of their wives in extramarital relationships. In some patriarchal cultures, male extramarital relations are accepted and often acts as a legitimate way to enhance self-esteem and masculinity (Silberschmidt, 2001), while in the case of women it disturbingly degrades men's social position concerning their masculine sexual image. Infidelity clearly breaches the ideals of trust and loyalties, a betrayal of a relationship, defiance of an agreement between two people (Pittman, 1989). The infidelity of a partner as a source of betrayal destabilises the marital relationships, invites harmful effects on individuals such anger, disappointment, depression, anxiety and distrust (Munsch, 2015), and collapses the solemn foundation of faith and morality in relationships (Jahan et al., 2017). This theme reflects that suicidal behaviour in men is the only way to end the pain, disrespect or loss of honour triggered by their partners' infidelity or extramarital relations (Krysinska, 2014). Earlier studies identified that the wife's infidelity or engagement with another relationship triggered men's suicidal behaviour (see Adinkrah, 2012; Knizek \& Hjelmeland, 2018). In the same vein, evidence from Bangladesh also confirms that infidelity triggers several problems in the existing relationship and invites severe consequences such as divorce, violence and suicide (Jahan et al., 2017). In addition, this study shows that reactive effects from the family members and community are important triggering factors of their suicidal behaviour (Asare-Doku et al., 2017). Family and community members might cast serious doubt about the sexual prowess of men as a reason for wife's involvement in infidelity. For any man, this could be a source of profound disgrace where sexuality is a source of power, and failure to meet standards may threaten a man's self-image/masculinity (Fracher \& Kimmel, 1995). A Bangladeshi study confirms that any distortion of the sexual image is a direct threat to masculinity (Khan et al., 2008), and societies attitude and cultural stigma invariably include critical messages for both masculine image and subsequent suicidal behaviour (Khan, Ratele, Helman et al., 2020). A study from Ghana confirms that men's sexual image provoked suicidal behaviour as it is considered a threat to hegemonic masculinity (Andoh-Arthur et al., 2018).

Involvement in a romantic relationship often contributes positively to life satisfaction and protection from suicidal behaviour, but it may also stand as a health-related risk factor when individuals become disappointed or estranged with their relationship (Till et al., 2017; Loving \& Slacher, 2013). The theme complications in non-marital romantic relationship taps into this association. There is a proposition that women demonstrate more suicidal behaviour than men as a result of the disturbance created by romantic relationships (Gold, 2012), but complexities and losses in romantic relationships could be an important risk factor in men's suicide as well (Canetto \& Lester, 2002). When the men's families obstructed their non-marital relationships it deeply disturbed them to the level of suicide. Obstruction created by the family members in romantic relationships confirms the fact that families may trigger suicidal behaviour (Murphy, 1999). In particular, 
complicated family relationships or physical abuse are strongly associated with suicidal behaviour (Ohtaki et al., 2019). For example, the distress imposed on men by their fathers (superior hegemony) complicates the situation, and physical abuse by their fathers is a source of humiliation and dishonour. Maintaining a sense of honour is integral to masculinity. A suicidal event is more likely to happen to a man if he loses his honour over relationship strain (Platt, 2017). These cases also provide reflections to how men suppressed through the interface between cultural expectations (e.g., not being involved in a romantic relationship) and personal choice/expectation (e.g., involved in a romantic relationship). It confirms that men are expected to sacrifice their own preferences and desires for the expectation of the supreme value of familism. Sacrifice involves subordinating one's own personal interests and incurring a personal loss that provides a positive benefit to others (Killen \& Turiel, 1998). For men it is an essential indicator of masculine ideology (Wilson, 2006).

Patriarchal norms and values in Bangladesh society attached a heightened notion of female subordination, subservience, subjugation and segregation (Sultana, 2011). No control, the final theme of the study provides contrary evidence of the lived Bangladeshi culture, whereby men encountered difficulties exercising authority over women. They were suppressed by the diverse controlling means and measures adopted by their wives and had essentially lost much of their patriarchal dividend or masculine image of domination. Their suicidal behaviour resulted from the perceived loss of selfesteem and respect as the patriarchal dividend failed to deliver the privileges to their manhood (Connell, 1995; Scourfield, 2005). An empirical evidence from Ghana confirms that loss of patriarchal control over wife and other conjugal cohabitants led to intimate partner violence and subsequently resulted in male suicide (Adinkrah, 2012). Another study from Uganda also confirmed that men opted for suicide when they had lost ultimate control over their spouse and family resources (Kizza et al., 2012). Men in our study fell into a state of defeat or entrapment in their intimate relationships which equates to a 'threat to perceived masculinity' or 'crisis in masculinity' (Anwary, 2015; Morgan, 2006). Loss of self-esteem and respect through entrapment, disempowerment and defeat is strongly associated with suicidal behaviour (Taylor et al., 2011).

\section{Limitations}

This article provides a partial view of the contextual praxis of men's suicide and attempted suicide only. We reiterate that this article is extracted from a larger study on masculinity and suicidal behaviour in Bangladesh through which we explored diverse cultural and social aspects of masculinity that stood as provoking factors of male suicidal behaviour. Relationship troubles in an intimate relationship are one aspect of those complexities. As the goal of this article is to illustrate men's experiences concerning intimate relationships only, we have restricted ourselves from highlighting other issues.

Secondly, as a qualitative study conducted in a specific rural location, findings cannot be taken for generalisation to a population of suicidal men in Bangladesh.

Thirdly, we do not disregard the possibility of recall/report biasness of this study. As only one person for each suicide case who is close to the deceased was interviewed, results could have been broadly triangulated if more 'significant others' close to the deceased were interviewed. 


\section{Conclusion}

Notwithstanding the limitations mentioned in the preceding paragraph, this study is unique to Bangladesh as no study has investigated the influence of intimate relationships on men's suicidal behaviour. This study provides an insightful subjective understanding of the way men's suicide and suicide attempt were triggered by the complexities and contestations associated with intimate relationships in the rural context. The findings of the study potentially contribute towards theoretical and methodological advances of suicide research. The several intersectional themes can broadly be explained under the discursive notion of 'hegemonic masculinity' which as a gendered practice provides explanations of the legitimacy of patriarchy and ensures the dominant position of men and the subordination of women (Connell, 1995). Hegemonic masculinity is the normative or ideal pattern of masculinity (Connell \& Messerschmidit, 2005). It differs as per cultural settings or places (e.g., small community or even a larger society) and it also varies over time and period (Barageine et al., 2015; Connell, 1995). Hegemonic masculinity acts as a symbolic benchmark that men follow in maintaining the gender order (Howson, 2006). The loss of power, position and gender identity as well as failing to attain hegemonic masculine ideals among men could develop inward rage and might be ended in suicide (Morgan, 2006; Mansdotter et al., 2009).

Although participants originated from the rural settings in one regional setting in Bangladesh, their experiences conflicted with the previously indicated Bangladeshi norms of hegemonic/ideal masculinity. In conditions men confronted difficulties in complex ways in maintaining or reinforcing the cultural mandate of hegemonic/ideal manhood status within intimate partnerships. In this sense, this idea may be conceived that men in this study demonstrated suicidal behaviour due to facing troubles in demonstrating their hegemonic ideals in multifaceted ways.

That confirms that they were estranged from the typical ideals of hegemonic masculinity and failed to live up to the masculine expectations and pressures. Maintaining the hegemonic masculine ideals or socially prescribed perfectionism in intimate relationship contexts were extremely problematic for them. Suicide was viewed by these men as a counteraction of the perceived threat to or a way out for not being able to live up to the demands of hegemonic masculinity in that particular location (Rivers, 2014).

The risks associated with intimate relationships demand much greater attention. In particular, lessons learnt from this study may be taken as a reference point for making suicide prevention strategy in Bangladesh by building a framework of positive gender and intimate relationship that will pay a critical attention to the everyday struggles of men. Such attention will lessen the burden on men's masculine expectations and promote an egalitarian social space to reduce the risks of suicide for men. Suicide and suicide attempt as revealed in the study are relational. Attention, thus, must be given to how these relationships are to be improved and strengthened to protect men and women from suicidal tendencies. We confirm that the conclusion of this study is drawn tentatively and cautiously and open to refutation or confirmation by future research. 


\section{Declaration}

The article is original, has not been published or submitted for publication elsewhere.

\section{Disclosure statement}

No potential conflict of interest was reported by the author(s).

\section{Notes on contributors}

Anisur Rahman Khan is Assistant Professor at the Department of Sociology, East West University, Bangladesh. His research interests include men and masculinity, sociology of suicide and social policy analysis.

Najuwa Arendse is Office Manager and Scientist at Institute for Social and Health Sciences, University of South Africa \& South African Medical Research Council-University of South Africa Masculinity and Health Research Unit, Cape Town, South Africa. Her research interest includes health promotion and injury prevention interventions. She is currently project manager of the National Injury Mortality Surveillance System (NIMSS).

Kopano Ratele is Director of the South African Medical Research Council Masculinity \& Health Research Unit and Professor at the University of South Africa. His research, teaching, sociopolitical activism, and community mobilisation focusses on men, boys and masculinity, violence, class, fatherhood, race and decolonial psychology.

\section{References}

Adinkrah, M. (2012). Better dead than dishonoured: Masculinity and male suicidal behaviour in contemporary Ghana. Social Science \& Medicine, 74, 474-481. https://doi.org/10.1016/j.socscimed. 2010.10.011

Ahluwalia, M. K., Walo-Roberts, S., \& Singh, A. A. (2015). Violence against women in the Sikh community. In A. J. Johnson (Ed.), Religion and men's violence against women (pp. 399-408). Springer.

Al-Krenawi, A., Slonim-Nevo, V., \& Graham, J. (2006). Polygyny and its impact on the psychosocial well-being of husbands. Journal of Comparative Family Studies, 37(2), 173-189. http://www.jstor. org/stable/41604069

Amin, S., \& Das, M. B. (2014). Marriage continuity and change in Bangladesh. In R. Kaur \& R. Palriwala (Eds.), Marrying in South Asia: Shifting concepts, changing practices in a globalising world (pp. 172-199). Orient Blackswan.

Andoh-Arthur, J., Kinizek, B. L., Osafo, J., \& Hjelmeland, H. (2018). Suicide among men in Ghana: The burden of masculinity. Death Studies, 42(10), 658-666. https://doi.org/10.1080/07481187.2018. 1426655

Anwary, A. (2015). Construction of hegemonic masculinity: Violence against wives in Bangladesh. Women's Studies International Forum, 50(May-June), 37-46. https://doi.org/10.1016/j.wsif.2015.02. 011

Arafat, S. M. Y. (2019). Females are dying more than males by suicide in Bangladesh. Asian Journal of Psychiatry, 4O(February), 124-125. https://doi.org/10.1016/j.ajp.2018.10.014

Asare-Doku, W., Osafo, J., \& Akotia, C. S. (2017). The experiences of attempt survivor families and how they cope after a suicide attempt in Ghana: A qualitative study. BMC Psychiatry, 17(1), (178). https://doi.org/10.1186/s12888-017-1336-9

Bachmann, S. (2018). Epidemiology of suicide and the psychiatric perspective. International Journal of Environmental Research and Public Health, 15(7), 1425. https://doi.org/10.3390/ijerph15071425 
Bagley, C. A., Shahnaz, A., \& Simkhada, P. (2017). High rates of suicide and violence in the lives of girls and young women in Bangladesh: Issues for feminist intervention. Social Sciences, 6(140), 1-17. https://doi.org/10.3390/socsci6040140

Bangladesh Bureau of Statistics. (2015). Age-sex composition of Bangladesh population: Population monograph: Volume 9. Bangladesh: Ministry of Planning. http://203.112.218.65:8008/ WebTestApplication/userfiles/Image/PopMonographs/Volume-9_Age-Sex.pdf

Bantjes, J., \& Kagee, A. (2013). Epidemiology of suicide in South Africa: Setting an agenda for future research. South African Journal of Psychology, 43(2), 238-251. https://doi.org/10.1177/ 0081246313482627

Barageine, J. K., Faxelid, E., Byamugisha, J. K., \& Rubenson, B. (2015). "As a man I felt small": A qualitative study of Ugandan men's experiences of living with a wife suffering from obstetric fistula. Culture, Health \& Sexuality, 18(4), 481-494. https://doi.org/10.1080/13691058.2015. 1089325

Bhandari, P., \& Titzmann, F. (2017). Introduction. Family realities in South Asia: Adaptations and resilience. South Asia Multidisciplinary Academic Journal, (16). https://doi.org/10.4000/samaj.4365

Bhuiya, A., Chowdhury, A. M. R., Momen, M., \& Khatun, M. (2005). Marital disruption: Determinants and consequences on the lives of women in a rural area of Bangladesh. Journal of Health, Population and Nutrition, 23(1), 82-94. https://pubmed.ncbi.nlm.nih.gov/15884756/

Braun, V., \& Clarke, V. (2006). Using thematic analysis in psychology. Qualitative Research in Psychology, 3(2), 77-101. https://doi.org/10.1191/1478088706qp063oa

Brooks, T. (2009). The problem with Polygamy. Philosophical Topics, 37(2), 109-122. https://doi.org/ 10.5840/philtopics20093727

Canetto, S. S., \& Lester, D. (2002). Love and achievement motives in women's and men's suicide notes. The Journal of Psychology: Interdisciplinary and Applied, 136(5), 573-576. https://doi.org/10. 1080/00223980209605552

Canham, S. L. (2009). The interaction of masculinity and control and its impact on the experience of suffering for an older man. Journal of Aging Studies, 23(2), 90-96. https://doi.org/10.1016/j.jaging. 2008.12.003

Chowdhury, F. (2009). Theorising patriarchy: The Bangladesh context. Asian Journal of Social Science, 37(4), 599-622. https://doi.org/10.1163/156853109X460200

Coleman, D., Kaplan, M. S., \& Casey, J. T. (2011). The social nature of male suicide. The International Journal of Men's Health, 10(3), 240-252. https://doi.org/10.3149/jmh.1003.240

Connell, R. W. (1995). Masculinities. University of California Press.

Connell, R. W., \& Messerschmidit, J. W. (2005). Hegemonic masculinities: Rethinking the concept. Gender and Society, 19(6), 829-859. https://doi.org/10.1177\%2F0891243205278639

Curtin, S. C., Warner, M., \& Hedegaard, H. (2016). Suicide rates for females and males by race and ethnicity: United States, 1999 and 2014. Centres for Disease Control and Prevention. https://www. cdc.gov/nchs/data/hestat/suicide/rates_1999_2014.pdf

Dasgupta, S. D. (2015). (Un)holy connections? Understanding woman abuse in Hinduism. In A. J. Johnson (Ed.), Religion and men's violence against women (pp. 371-382). Springer.

Delgado, K. J. (2012). The role of relationships in completed suicide: A gendered analysis of suicide notes. Wright State University. https://pdfs.semanticscholar.org/0883/a7e695560ea8f669f977 cee347a2db1a4f1a.pdf

Donner, H. (2014). Gender and property in neoliberal middle-class Kolkata. In L. Fernandes (Ed.), Routledge handbook of gender in South Asia (pp. 189-204). Routledge.

Durkheim, E. (1897/2005). Suicide. Routledge.

Evans, R., Scourfield, J., \& Moore, G. (2016). Gender, relationship breakdown, and suicide risk. Journal of Family Issues, 37(16), 2239-2264. https://doi.org/10.1177/0192513X14562608

Fracher, J., \& Kimmel, M. S. (1995). Hard issues and soft spots: Counselling men about sexuality. In M. S. Kimmel \& M. Messner (Eds.), Men's lives (pp. 365-374). Allyn and Bacon.

Gangoli, G., \& Rew, M. (2011). Mothers-in-law against daughters-in-law: Domestic violence and legal discourses around mother-in-law violence against daughters-in-law in India. Women's Studies International Forum, 34(5), 420-429. https://doi.org/10.1016/j.wsif.2011.06.006 
Gillies, V. (2003). Family and intimate relationships: A review of the sociological research. South Bank University.

Gold, L. H. (2012). Suicide and gender. In R. I. Simon \& R. E. Hales (Eds.), Textbook of suicide assessment and management (pp. 453-480). American Psychiatric Publishing.

Griffiths, G., Ladva, G., Brock, A., \& Baker, A. (2008). Trends in suicide by marital status in England and Wales, 1982-2005. Office for National Statistics. https://pdfs.semanticscholar.org/2f98/a91f23a3b f5e250e64c44f72356538c0536b.pdf

Hasan, K., Aggleton, P., \& Persson, A. (2017). The makings of a man: Social generational masculinities in Bangladesh. Journal of Gender Studies, 27(3), 347-361. https://doi.org/10.1080/09589236.2017. 1388773

Hawton, K., \& Van Heeringen, K. (2009). Suicide. Lancet, 373(9672), 1372-1381. https://doi.org/10. 1016/S0140-6736(09)60372-X

Hjelmeland, H., \& Knizek, B. L. (2019). The emperor's new clothes? A critical look the interpersonal theory of suicide. Death Studies. 44(3), 168-178. https://doi.org/10.1080/07481187.2018.1527796

Howson, R. (2006). Challenging hegemonic masculinity. Routledge.

Ide, N., Wyder, M., Kolves, K., \& De Leo, D. (2010). Separation as an important risk factor for suicide: A systematic review. Journal of Family Issues, 31(12), 1689-1716. https://doi.org/10.1177/ $0192513 \times 10365317$

Imtiaz, S. S. (2013). Ordinary men's constructions of masculinity: Exploration of constructions of masculinity in extreme poor household in Northeast Bangladesh. CARE Bangladesh. http://www. care.org/sites/default/files/documents/Bangladesh\%20EMI\%20report.pdf.

Jahan, N. (2019, September 27). Jhenaidah: A death a day. The Daily Star. https://www.thedailystar. net/star-weekend/spotlight/news/jhenaidah-death-day-1805575

Jahan, Y., Chowdhury, A. S., Rahman, A. S. M., Chowdhury, S., Khair, Z., Huq, K. A. T. M. E., \& Rahman, M. M. (2017). Factors involving extramarital affairs among married adults in Bangladesh. Int J Community Med Public Health, 4(5), 1379-1386. https://doi.org/10.18203/ 2394-6040.ijcmph20171506

Jamieson, L. (2011). Intimacy as a concept: Explaining social change in the context of globalisation or another form of ethnocentricism? Sociological Research Online, 16(4), 15. https://doi.org/10. $5153 /$ sro. 2497

Karim, R., Lindberg, L., Wamala, S., \& Emmelin, M. (2018). Men's perceptions of women's participation in development initiatives in rural Bangladesh. American Journal of Men's Health, 12(2), 398-410. https://doi.org/10.1177/1557988317735394

Kazan, D., Alison, A. L., \& Batterham, P. J. (2015). The impact of intimate partner relationships on suicidal thoughts and behaviours: A systematic review. Journal of Affective Disorders, 90, 585-598. https://doi.org/http://dx.doi.org/10.1016/j.jad.2015.11.003

Khan, A. R., \& Khandaker, S. (2017). Analysing masculinity from the key theoretical lenses and searching for linkages with violence against women. Masculinities and Social Change, 6(3), 257-287. http://dx.doi.org/10.17583/mcs.2017.2593

Khan, A. R., Ratele, K., \& Arendse, N. (2020). Men's reflections on postsuicide attempt episode in Bangladesh. OMEGA - Journal of Death and Dying, 003022282090487. https://doi.org/10.1177/ 0030222820904878

Khan, A. R., Ratele, K., Arendse, N., Islam, M. Z., \& Dery, I. (2020). Suicide and attempted suicide in Jhenaidah district. Bangladesh, 2010-2018. Crisis: The Journal of Crisis Prevention and Suicide Prevention, 41(4), 304-312. https://doi.org/10.1027/0227-5910/a000631

Khan, A. R., Ratele, K., Helman, R., Dlamini, S., \& Makama, R. (2020). Masculinity and suicide in Bangladesh. OMEGA-Journal of Death and Dying, 003022282096623. https://doi.org/10.1177/ 0030222820966239

Khan, M. E., \& Townsend, J. W. (2014). Representation of the masculine identity in Bangladesh. In M. E. Khan, J. W. Townsend, \& P. J. Pelto (Eds.), Sexuality, gender roles, and domestic violence in South Asia (pp. 113-132). Population Council.

Khan, M. M. (2002). Suicide on the Indian subcontinent. Crisis: The Journal of Crisis Prevention and Suicide Prevention, 23(3), 104-107. https://doi.org/10.1027//0227-5910.23.3.104 
Khan, M. M., Asad, N., \& Syed, E. U. (2011). Suicide in Asia: Epidemiology, risk factors, and prevention. In R. C. O'Connor, S. Platt, \& J. Gordon (Eds.), International handbook of suicide prevention: Research, policy and practice (pp. 524-540). Wiley.

Khan, S. I., Hudson-Rodd, N., Saggers, S., Islam, B. M. I., Karim, S. A., \& Rauyajin, O. (2008). Phallus, performance and power: Crisis of masculinity. Sexual and Relationship Therapy, 23(1), 37-49. https://doi.org/10.1080/14681990701790635

Killen, M., \& Turiel, E. (1998). Adolescents' and young adults' evaluations of helping and sacrificing for others. Journal of Research on Adolescence, 8(3), 355-375. https://doi.org/10.1207/ s15327795jra0803_4

Kizza, D., Knizek, B. L., Kinyanda, E., \& Hjelmeland, H. (2012). Men in despair: A qualitative psychological autopsy study of suicide in Northern Uganda. Transcultural Psychiatry, 49(5), 696-717. https://doi.org/10.1177/1363461512459490

Knizek, B. L., \& Hjelmeland, H. (2018). To die or not to die: A qualitative study of men's suicidality in Norway. BMC Psychiatry, 18(1), 263. https://doi.org/10.1186/s12888-018-1843-3

Krysinska, K. (2014). Men and suicide: An overview. In D. Lester, J. F. Gunn III, \& P. Quinnett (Eds.), Suicide in men: How men differ in expressing their distress (pp. 5-24). Charles C Thomas Publisher Ltd.

Lönnqvist, J. (2016). Physical illnesses and suicide. In D. Wasserman (Ed.), Suicide: An unnecessary death (pp. 125-131). Oxford university press.

Loving, T. J., \& Slacher, R. B. (2013). Romantic relationships and health. In J. A. Simpson \& L. Campbell (Eds.), The Oxford handbook of close relationships (pp. 617-637). Oxford University Press.

Macia, M., Maharaj, P., \& Gresh, A. (2011). Masculinity and male sexual behaviour in Mozambique. Culture, Health \& Sexuality, 13(10), 1181-1192. https://doi.org/10.1080/ 13691058.2011.611537

Mansdotter, A., Lundin, A., Falkstedt, D., \& Hemmingsson, T. (2009). The association between masculinity rank and mortality patterns: A prospective study based on the Swedish 1969 conscript cohort. Journal of Epidemiology \& Community Health, 63(5), 408-413. https://doi.org/10. 1136/jech.2008.082628

Mashreky, S. R., Rahman, F., \& Rahman, A. (2013). Suicide kills more than 10,000 people every year in Bangladesh. Archives of Suicide Research, 17(4), 387-396. https://doi.org/10.1080/13811118.2013. 801809

Mathewson, S. H. (2009). Man is the remedy of man: Constructions of masculinity and health related behaviours among young men in Dakar, Senegal. London School of Economics and Political Studies. http://www2.Ise.ac.uk/internationalDevelopment/pdf/WP91.pd

Mayer, P. (2012). Suicide and society in India. Routledge.

Mittra, S., \& Kumar, B. (2004). Encyclopaedia of women in South Asia: Maldives. Kalpaz Publications.

Moham, E. (2020). The oppression of South Asian women and their clinical implications. California Southern University. https://search.proquest.com/openview/4f158a4fd147c06b06fa9cf bad51c20d/1?pq-origsite $=$ gscholar $\& \mathrm{cbl}=18750 \&$ diss $=y$

Möller-Leimkühler, A. M. (2003). The gender gap in suicide and premature death or: Why are men so vulnerable? European Archives of Psychiatry and Clinical Neuroscience, 253(1), 1-8. https://doi.org/ 10.1007/s00406-003-0397-6

Morgan, D. (2006). The crisis in masculinity. In K. Davis, M. Evans, \& J. Lorber (Eds.), Handbook of Gender and Women's Studies (pp. 109-124). Sage.

Munsch, C. L. (2015). Her support, his support: Money, masculinity, and marital infidelity. American Sociological Review, 80(3), 469-495. https://doi.org/10.1177/0003122415579989

Murphy, J. M. (1999). Coping with teen suicide. The Rosen Publishers Group, Inc.

Ohtaki, Y., Doki, S., Kaneko, H., Hirai, Y., Oi, Y., Sasahara, S., \& Matsuzaki, I. (2019). Relationship between suicidal ideation and family problems among young callers to the Japanese crisis hotline. Plos One, 14(7), e0220493. https://doi.org/10.1371/journal.pone.0220493

Olley, B. O. (2004). Predictors of hazardous and harmful alcohol use among Nigerian freshmen. African journal of medicine and medical sciences, 33(4), 327-333. 
Omololu, F. O., Aderinto, Y., Adeyefa, I., Adeyemo, D., \& Osotimehin, B. (2004). Social construction of manhood in Nigeria: Implications for male responsibility in reproductive health. African Population Studies, 19(2), 1-20. https://tspace.library.utoronto.ca/handle/1807/4108.

Pittman, F. S. (1989). Private lies: Infidelity and the betrayal of intimacy. Replica Books.

Platt, S. (2017). Suicide in men: What is the problem? Trends in Urology and Men's Health, 8(July/ August), 9-12. https://doi.org/10.1002/tre.587

Pollock, N. J., Apok, C., Concepcion, T., Delgado Jr, R. A., Jr, Rasmus, S., Chatwood, S., \& Collins, P. Y. (2020). Global goals and suicide prevention in the circumpolar North. Indian Journal of Psychiatry, 62(1), 7-14. https://doi.org/10.4103/psychiatry.IndianJPsychiatry_717_19

Ragonese, C., Shand, T., \& Barker, G. (2019). Masculine norms and men's health: Making the connections. Promundo-US.

Rahim, A. K. M. A. (2015). Fight against suicide. Journal of Enam Medical College, 5(1), 4-5. https://doi. org/http://dx.doi.org/10.3329/jemc.v5i1.21490

Rahman, H. (1988). Socio-economic and psychological causes of suicide in Jhenaidah District. Northern Book Centre.

Rao, N. (2012). Breadwinners and homemakers: Migration and changing conjugal expectations in rural Bangladesh. Journal of Development Studies, 48(1), 26-40. https://doi.org/10.1080/00220388. 2011.629648

Rathod, S. D., Kingdon, N., Pinninti, D. T., \& Phiri, P. (2015). Cultural adaptation of CBT for serious mental illness: A guide for training and practice. Willey.

Rivers, J. (2014). Suicide and hegemonic masculinity in Australian men. In D. Lester, J. F. Gunn III, \& P. Quinnett (Eds.), Suicide in men (pp. 248-261). Charles C. Thomas.

Roberts, B. W., \& Robins, R. W. (2000). Broad dispositions, broad aspirations: The intersection of personality traits and major life goals. Personality and Social Psychology Bulletin, 26(10), 1284-1296. https://doi.org/10.1177/0146167200262009

Sadek, A., Anam, A. M. A., Rashid, M. S. A., Akber, E. B., \& Khan, N. T. (2019). Suicide kills more peoples than any other forms of violence. Mediscope, 6(2), 87-92. https://doi.org/10.3329/mediscope.v6i2. 43158

Schrijvers, D. L., Bollen, J., \& Sabbe, B. G. C. (2012). The gender paradox in suicidal behaviour and its impact on the suicidal process. Journal of Affective Disorders, 138(1-2), 19-26. https://doi.org/10. 1016/j.jad.2011.03.050

Scourfield, J. (2005). Suicidal masculinities. Sociological Research Online, 10(2), 1-14. https://doi.org/ $10.5153 /$ sro. 1057

Scourfield, J., \& Evans, R. (2014). Why might men be more at risk of suicide after a relationship breakdown? Sociological insights. American Journal of Men's Health, 9(5), 380-384. https://doi. org/10.1177\%2F1557988314546395

Shah, C. D. (2016). South Asian women's sexual relationship power: Examining the role of sexism, cultural values conflict, discrimination, and social support [Open Access Dissertations]. Purdue University. https://docs.lib.purdue.edu/open_access_dissertations/843

Shenk, M., Towner, M., Voss, E., \& Alam, N. (2016). Consanguineous marriage, kinship ecology, and market transition. Current Anthropology, 57(S13), S167-S180. https://doi.org/10.1086/ 685712

Shiner, M., Scourfield, J., Fincham, B., \& Langer, S. (2009). When things fall apart: Gender and suicide across the life-course. Social Science \& Medicine, 69(5), 738-746. https://doi.org/10.1016/j.socs cimed.2009.06.014

Silberschmidt, M. (2001). Disempowerment of men in rural and urban East Africa: Implications for male identity and sexual behaviour. World Development, 29(4), 651-657. https://doi.org/10.1016/ S0305-750X(00)00122-4

Spring, J. A., \& Spring, M. (1997). After the affair: Healing the pain and rebuilding trust when a partner has been unfaithful. Harper Perennial.

Srivastava, S., \& Roy, R. (2011). Understanding masculinities. In R. Roy \& S. Srivastava (Eds.), Understanding masculinities: Culture, politics and social change (pp. 1-19). SANAM.

Stack, S. (1982). Suicide: A decade of sociological literature. Deviant Behaviour, 4(1), 41-66. https:// doi.org/10.1080/01639625.1982.9967602 
Sultana, A. (2011). Patriarchy and women's subordination: A theoretical analysis. The Arts Faculty Journal, 4, 1-18. https://doi.org/10.3329/afj.v4i0.12929

Sultana, N., \& Karim, A. (2013). Women in Bangladesh: A journey of stages. In C. Fluehr-Lobban \& J. M. Billson (Eds.), Female well-being: Toward a global theory of social change. Zed Books.

Taylor, P. J., Gooding, P., Wood, A. M., \& Tarrier, N. (2011). The role of defeat and entrapment in depression, anxiety, and suicide. Psychological Bulletin, 137(3), 391-420. https://doi.org/10.1037/ a0022935

Till, B., Tran, U. S., \& Niederkrotenthaler, T. (2017). Relationship Satisfaction and Risk Factors for Suicide. Crisis, 38(1), 7-16. https://doi.org/10.1027/0227-5910/a000407

Vera-Sanso, P. (1999). Dominant daughters-in-law and submissive mothers-in-law? Cooperation and conflict in South India. The Journal of the Royal Anthropological Institute, 5(4), 577. https://doi.org/ $10.2307 / 2661149$

Wasserman, D. (2016a). Suicide risk assessment. In D. Wasserman (Ed.), Suicide an unnecessary death (pp. 232-239). Oxford university press.

Wasserman, D. (2016b). Suicidal people's experiences of trauma and negative life events. In D. Wasserman (Ed.), Suicide an unnecessary death (pp. 145-150). Oxford university press.

White, S. C. (2017). Patriarchal investments: Marriage, dowry and the political economy of development in Bangladesh. Journal of Contemporary Asia, 47(2), 247-272. https://doi.org/10.1080/ 00472336.2016 .1239271

Wilson, D. (2006). For a glory and a covering: A practical theology of marriage. Canon Press.

World Health Organisation. (2014). Preventing suicide: A global imperative. World Health Organization (WHO). http://apps.who.int/iris/bitstream/10665/131056/8/9789241564878_eng. pdf?ua $=1 \&$ ua $=1$

World Health Organisation. (n.d.). Age-Standardized suicide rates (per 100,000). World Health Organization (WHO). https://www.who.int/data/gho/data/indicators/indicator-details/GHO/agestandardized-suicide-rates-(per-100-000-population)

Wyder, M., Ward, P., \& De Leo, D. (2009). Separation as a suicide risk factor. Journal of Affective Disorders, 116(3), 208-213. https://doi.org/10.1016/j.jad.2008.11.007

Yeung, W. J., Desai, S., \& Jones, J. W. (2018). Families in Southeast and South Asia. Annual Review of Sociology, 44(1), 469-495. https://doi.org/10.1146/annurev-soc-073117-041124

Yusuf, H. R., Akhter, H. H., Rahman, M. H., Chowdhury, M. K., \& Rochat, R. W. (2000). Injury related deaths amongst women aged 10-50 years in Bangladesh, 1996-97. Lancet, 355(9211), 1220-1224. https://doi.org/10.1016/S0140-6736(00)02088-2 